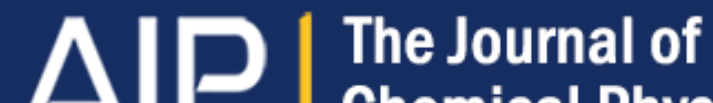 Chemical Physics
}

\section{Electronic excitation and oscillator strength of ethyl iodide by VUV photoabsorption and electron energy loss spectroscopy}

A. Giuliani, F. Motte-Tollet, J. Delwiche, J. Heinesch, N. J. Mason, J. M. Gingell, I. C. Walker, N. C. Jones, and M.-J. Hubin-Franskin

Citation: The Journal of Chemical Physics 110, 10307 (1999); doi: 10.1063/1.478964

View online: http://dx.doi.org/10.1063/1.478964

View Table of Contents: http://scitation.aip.org/content/aip/journal/jcp/110/21 ?ver=pdfcov

Published by the AIP Publishing

\section{Articles you may be interested in}

Electronic excitation of furfural as probed by high-resolution vacuum ultraviolet spectroscopy, electron energy loss spectroscopy, and ab initio calculations

J. Chem. Phys. 143, 144308 (2015); 10.1063/1.4932603

Electronic excitation of carbonyl sulphide (COS) by high-resolution vacuum ultraviolet photoabsorption and electron-impact spectroscopy in the energy region from 4 to $11 \mathrm{eV}$

J. Chem. Phys. 142, 064303 (2015); 10.1063/1.4907200

2-methyl furan: An experimental study of the excited electronic levels by electron energy loss spectroscopy, vacuum ultraviolet photoabsorption, and photoelectron spectroscopy

J. Chem. Phys. 119, 3670 (2003); 10.1063/1.1590960

Electronic excitation and optical cross sections of methylamine and ethylamine in the UV-VUV spectral region J. Chem. Phys. 116, 9261 (2002); 10.1063/1.1473820

Electronic excitation and oscillator strength of ethyl bromide by vacuum ultraviolet photoabsorption and electron energy loss spectroscopy

J. Chem. Phys. 112, 6285 (2000); 10.1063/1.481273

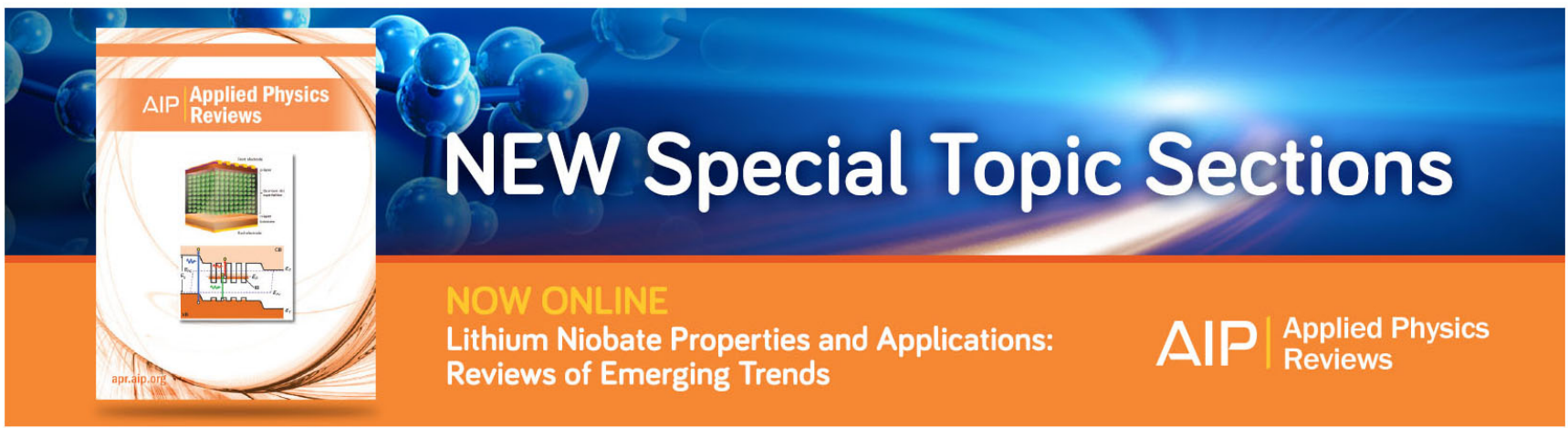




\section{Electronic excitation and oscillator strength of ethyl iodide by VUV photoabsorption and electron energy loss spectroscopy}

A. Giuliani and F. Motte-Tollet

Laboratoire de Spectroscopie d'Electrons diffusés, Université de Liège, Institut de Chimie-Bât. B6c, B-4000 Liège, Belgium

J. Delwiche

Thermodynamique et Spectroscopie, Université de Liège, Institut de Chimie-Bât. B6c, B-4000 Liège, Belgium

J. Heinesch

Laboratoire de Spectroscopie d'Electrons diffusés, Université de Liège, Institut de Chimie-Bât. B6C, B-4000 Liège, Belgium

N. J. Mason

Department of Physics and Astronomy, University College London, Gower Street, London WC1E 6BT, United Kingdom

J. M. Gingell

Department of Chemistry, Christopher Ingold Laboratories, 20 Gordon Street, London WC1H OAJ, United Kingdom

I. C. Walker

Department of Chemistry, Heriot-Watt University, Riccarton, Edinburgh EH14 4AS, United Kingdom

N. C. Jones

Department of Physics and Astronomy, University College London, Gower Street, London WClE 6BT, United Kingdom

M.-J. Hubin-Franskin ${ }^{\text {a) }}$

Laboratoire de Spectroscopie d'Electrons diffusés, Université de Liège, Institut de Chimie-Bât. B6C, B-4000 Liège, Belgium

(Received 29 December 1998; accepted 3 March 1999)

A high resolution VUV photoabsorption spectrum of ethyl iodide has been recorded between 4 and $10.2 \mathrm{eV}(310-120 \mathrm{~nm})$ using synchrotron radiation. The spectrum consists of a broad structureless absorption band centered at $4.78 \mathrm{eV}$, followed by a region dominated by excitation of Rydberg states. A high resolution photoelectron spectrum (PES) of the lowest energy ionization band has been obtained and provides ionization energies necessary for identification of related Rydberg-excited states. Also, analysis of the vibrational fine structure in the PES has allowed identification of the normal vibrational modes excited and their wave numbers in the ion. These, in turn, have been used in the assignment of the lowest energy photoabsorption bands arising from electron excitation into the $6 s$ Rydberg orbital. An electron energy loss spectrum has also been recorded from 5.8 to $14.2 \mathrm{eV}$, under electric-dipole conditions. It confirms the magnitude of the photoabsorption cross section values obtained using the synchrotron radiation and extends the differential and optical oscillator strength values up to $14.2 \mathrm{eV}$. (C) 1999 American Institute of Physics. [S0021-9606(99)01220-9]

\section{INTRODUCTION}

During the last two decades, the spectroscopy of the alkyl iodide family has been the topic of many experimental studies. The UV absorption spectra of these molecules show a weak broadband at low excitation energies, traditionally labeled the $A$ band and assigned to electron promotion into the antibonding orbital $\sigma^{*}(\mathrm{C}-\mathrm{I})$, the electronic states formed being dissociative along the $\mathrm{C}-\mathrm{I}$ bond. These molecular states offer selective photochemistry possibilities ${ }^{1}$ and since they can be photolyzed in the atmosphere at a

${ }^{\text {a) }}$ Directeur de recherche F.N.R.S. lower altitude than the chlorofluorohydrocarbons (CFCs), they may play a role in some ozone depletion processes. ${ }^{2-4}$ Methyl iodide and ethyl iodide are also model systems for the investigation of bonding molecules onto a surface. ${ }^{5,6}$

The first spectroscopic studies of ethyl iodide were performed in the 1930s. ${ }^{7,8}$ Since then, the UV photoabsorption spectra and molar extinction coefficients have been reported between $3.7 \mathrm{eV}$ and $9.9 \mathrm{eV}$. ${ }^{9}$ The spectra have been interpreted mainly in terms of electronic band origins and vibrational levels for the lowest energy Rydberg states. ${ }^{9}$ The spectrum resembles that of methyl iodide, being dominated by iodine atom features so that ethyl iodide, as well as higher alkyl iodides, may be studied in the $C_{3 v}$ point group. In this, 
the highest occupied orbitals are a pair of doubly degenerate $e$ orbitals (lone pair) localized on the iodine atom. In ethyl iodide, the two lowest energy Rydberg bands $\left(e^{3} 6 s^{1}\right)$ observed by photoabsorption ${ }^{10}$ have been taken to arise from excitation of states $E(1)$ and $E(2)$ for the ion ${ }^{2} E_{3 / 2}$ limit, and of states $A_{1}$ and $E(3)$ for the ${ }^{2} E_{1 / 2}$ limit. The transitions to the $E(1)$ and $E(3)$ states are optically allowed and responsible for the most intense features. Excitation to $A_{1}$ and $E(2)$ are $Q$ branch forbidden and $\Delta \Omega$ forbidden, respectively, and have been assigned to low intensity features, at least for the electronic origin. These assignments have been supported, both for the energetic ordering and the symmetry, by two-photon resonant multiphoton ionization and laser polarization studies ${ }^{11}$ which also confirm that the local $C_{3 v}$ symmetry environment is a valid approximation for ethyl iodide. Spectra in the region of the first Rydberg transition have been recorded using resonant enhanced multiphoton ionization and a molecular jet. ${ }^{12}$ They have been interpreted in terms of the $E(1)$ and $E(2)$ states for the lowest energy region $(6.15-6.42 \mathrm{eV})$, each split into the $A^{\prime}$ and $A^{\prime \prime}$ components in the $C_{s}$ point group by $0.0299 \mathrm{eV}$ and $0.0233 \mathrm{eV}$, respectively. Over the $6.69 \mathrm{eV}-6.95 \mathrm{eV}$ region, these workers placed the electronic origin of the $A_{1}$ state at a higher energy than that of $E(3)$, and reported a splitting of 0.0285 $\mathrm{eV}$ for the $A^{\prime}$ and $A^{\prime \prime}$ components. A single-photon absorption spectrum in the $7.10 \mathrm{eV}-10.2 \mathrm{eV}$ region recorded at high resolution has been interpreted with the help of multichannel quantum defect calculations ${ }^{13}$ in terms of the $n s, n d$, and $n p$ series converging to the ${ }^{2} E_{3 / 2}$ and ${ }^{2} E_{1 / 2}$ ionic limits, providing a quasi-atomic ordering of the Rydberg excitations. Finally, the electronic excitation spectrum of ethyl iodide has been explored by electron impact, the electron energy loss spectrum covering a broader energy range than the photoabsorption spectra but with a lower resolution; this identified a new Rydberg series at high energy and confirmed the presence of the ${ }^{3} Q_{1}(E)$ valence state at $4.1 \mathrm{eV}^{14}$

In this paper, we report new data on the electronic spectroscopy and absorption cross sections of ethyl iodide in the $4 \mathrm{eV}-14.2 \mathrm{eV}$ region. We have made use of two experimental methods: (1) high resolution VUV photoabsorption using synchrotron radiation to provide absolute cross sections; and (2) electron energy loss spectroscopy in dipolar excitation conditions to provide relative excitation cross sections at higher excitation energies.

The high resolution photoabsorption features in the region of the $6 s$ Rydberg transitions have been interpreted by comparison of the shape of the corresponding absorption bands with that of the He I photoelectron spectrum of the HOMO. The latter, reported here for the first time at high resolution, provides the ionization energies together with the normal vibrational frequencies of the molecular ion. These data have been used to help in the assignment of the vibrational fine structure accompanying the transitions to the first Rydberg states observed in the VUV spectrum.

\section{EXPERIMENTAL METHODS}

\section{A. Photoelectron spectroscopy}

The photoelectron spectrometer used in these measurements is described in detail elsewhere. ${ }^{15,16}$ It is fitted with a $180^{\circ}$ hemispherical electrostatic analyzer, working in the constant pass-energy mode. The He I photons $(58.4 \mathrm{~nm})$ are produced through a dc discharge in helium in a two-stage differentially pumped lamp. The spectrum was recorded by sweeping the retarding voltage between the chamber and the entrance slit of the analyzer in $2 \mathrm{meV}$ steps. The spectra were corrected for the transmission of the analyzing system. The resolution was about $25 \mathrm{meV}$ and the ionization energy scale was calibrated using the xenon peaks $\left({ }^{2} P_{3 / 2}: 12.123 \mathrm{eV}\right.$ and $\left.{ }^{2} P_{1 / 2}: 13.436 \mathrm{eV}^{17}\right)$. The raw PE spectrum was deconvoluted in order to resolve more clearly some features appearing as shoulders and to provide them with more precise energy values. The deconvolution procedure was the Van Cittert method ${ }^{18}$ and Allen and Grimm's algorithm. ${ }^{19}$ The $\mathrm{Xe}^{+2} P_{3 / 2}$ peak was assumed to mimic the instrumental profile.

\section{B. Optical absorption}

The VUV photoabsorption spectrum was recorded at the synchrotron radiation source of Daresbury (U.K.) using the Daresbury Laboratory Molecular Science Absorption Apparatus (DLMSAA) coupled to beam line 3.1. ${ }^{20}$ Synchrotron radiation was dispersed by a Seya-Namioka monochromator, and kept in UHV conditions by an ion pump. The light enters the absorption cell through a $\mathrm{LiF}$ window. The absorption cell is composed of a six-way cross system upon which are fitted the sample inlet, an outlet coupled to a turbo-molecular pump, the Baratron pressure gauge, and the entrance and exit windows for the synchrotron light. The absorption path length is $16 \mathrm{~cm}$. The radiation leaves the cell through a LiF window. The spectral range extended from $4 \mathrm{eV}(310 \mathrm{~nm})$ to $10.2 \mathrm{eV}(120 \mathrm{~nm})$ and was covered by a series of $25 \mathrm{~nm}$ sections, each scanned with $0.05 \mathrm{~nm}$ steps. At each wavelength the transmitted radiation, $I_{t}$, was recorded, as well as the sample pressure and the electron beam current of the storage ring. The cell was then emptied and $I_{0}$, the radiation intensity through the empty cell, was recorded in the same conditions. $I_{t}$ and $I_{0}$ were normalized to unitary beam current.

The absolute photoabsorption cross section $\sigma_{\mathrm{pa}}$ was obtained by using the Beer-Lambert law:

$$
I_{t}=I_{0} \exp \left(-\sigma_{\mathrm{pa}} N x\right),
$$

where $N$ is the target gas number density and $x$ is the path length.

\section{Electron energy loss spectroscopy (EELS)}

The instrument used (VG-SEELS 400) has been described in detail elsewhere. ${ }^{21-23}$ Briefly, an electrostatic electron energy monochromator fitted with a three element lens produces a collimated electron beam, defines a narrow energy spread about the mean energy, and focuses the electrons into the collision region. The electron beam intersects the gas beam which flows through an hypodermic needle at $90^{\circ}$. The analyzer system is of the same type as the monochromator. Both electron energy selectors work in the constant passenergy mode. The signal is detected by an electron multiplier of the continuous dynode type. The ethyl iodide spectrum was recorded between $5.8 \mathrm{eV}$ and $14.4 \mathrm{eV}$ with steps of 8 
TABLE I. Symmetry, wave numbers $\left(\mathrm{cm}^{-1}\right)$, energy (eV), and description of the normal vibrational modes of $\mathrm{C}_{2} \mathrm{H}_{5} \mathrm{I}$ in its electronic ground state (Ref. 25).

\begin{tabular}{ccll}
\hline \hline Assignation & $\begin{array}{r}\text { Wave number } \\
\left(\mathrm{cm}^{-1}\right)\end{array}$ & $\begin{array}{l}\text { Energy } \\
(\mathrm{eV})\end{array}$ & \multicolumn{1}{c}{ Description } \\
\hline$\nu_{1}\left(a^{\prime}\right)$ & 2986 & 0.370 & $\mathrm{CH}_{3}$ antisymmetric stretch \\
$\nu_{2}\left(a^{\prime}\right)$ & 2973 & 0.369 & $\mathrm{CH}_{2}$ symmetric stretch \\
$\nu_{3}\left(a^{\prime}\right)$ & 2932 & 0.364 & $\mathrm{CH}_{3}$ symmetric stretch \\
$\nu_{4}\left(a^{\prime}\right)$ & 1462 & 0.181 & $\mathrm{CH}_{3}$ antisymmetric deformation \\
$\nu_{5}\left(a^{\prime}\right)$ & 1439 & 0.178 & $\mathrm{CH}_{2}$ scissors \\
$\nu_{6}\left(a^{\prime}\right)$ & 1385 & 0.172 & $\mathrm{CH}_{3}$ symmetric deformation \\
$\nu_{7}\left(a^{\prime}\right)$ & 1207 & 0.150 & $\mathrm{CH}_{2}$ wag \\
$\nu_{8}\left(a^{\prime}\right)$ & 1054 & 0.131 & $\mathrm{CH}_{3}$ in-plane rock \\
$\nu_{9}\left(a^{\prime}\right)$ & 957 & 0.119 & $\mathrm{C}_{-} \mathrm{C}$ stretch \\
$\nu_{10}\left(a^{\prime}\right)$ & 509 & 0.063 & $\mathrm{C}_{-1}$ stretch \\
$\nu_{11}\left(a^{\prime}\right)$ & 258 & 0.032 & $\mathrm{C}-\mathrm{I}$ bend $\left.^{\prime}\right)$ \\
$\nu_{12}\left(a^{\prime \prime}\right)$ & 3025 & 0.375 & $\mathrm{CH}_{2}$ antisymmetric stretch \\
$\nu_{13}\left(a^{\prime \prime}\right)$ & 2989 & 0.371 & $\mathrm{CH}_{3}$ antisymmetric stretch \\
$\nu_{14}\left(a^{\prime \prime}\right)$ & 1447 & 0.179 & $\mathrm{CH}_{3}$ antisymmetric deformation \\
$\nu_{15}\left(a^{\prime \prime}\right)$ & 1201 & 0.149 & $\mathrm{CH}_{2}$ twist \\
$\nu_{16}\left(a^{\prime \prime}\right)$ & 1015 & 0.126 & $\mathrm{CH}_{3}$ out-of-plane rock \\
$\nu_{17}\left(a^{\prime \prime}\right)$ & 741 & 0.092 & $\mathrm{CH}_{2}$ rock \\
$\nu_{18}\left(a^{\prime \prime}\right)$ & 258 & 0.032 & $\mathrm{CH}_{3}$ torsion \\
\hline \hline
\end{tabular}

$\mathrm{meV}$ and a resolution of about $36 \mathrm{meV}$. The operating pressure was $1.5 \times 10^{-5}$ mbar during the measurements. The apparatus was used with high incident energy electrons (100 $\mathrm{eV})$ and at a small scattering angle $\left(\theta \approx 0^{\circ}\right)$, such that dipole $(e, e)$ conditions apply and the energy loss spectrum is comparable with the photoabsorption spectrum. The inelastic scattered intensity was converted to a relative differential oscillator strength (DOS) distribution, $d f / d E$, using the method developed previously: ${ }^{24}$

$$
\frac{d f}{d E} \propto \frac{E}{R} \hat{\theta}\left\{\ln \left[1+\left(\frac{\hat{\theta}}{\gamma}\right)^{2}\right]\right\}^{-1} I(E),
$$

where $\gamma=(E / 2 T)^{2}(1-E / T)^{-1}, T$ is the incident energy, $E$ is the electron energy loss, $I(E)$ is the scattered intensity, $\hat{\theta}$ is the spectrometer angular acceptance $\left(1.25^{\circ} \pm 0.25\right.$ in this work), and $R$ is one Rydberg.

To obtain absolute values, the EELS data must be normalized to a known cross section at a particular wavelength measured in the optical experiment. The cross section may then be calculated from:

$$
\sigma_{\mathrm{pa}}=109.75 \frac{d f}{d E},
$$

where $\sigma_{\mathrm{pa}}$ is in Mbarn and $d f / d E$ is in $\mathrm{eV}^{-1}$.

The comparison of the EELS cross section values with those recorded using the synchrotron source provides a test for any systematic error in the optical values arising from the line saturation effect and second order light from the light source and beam line. These effects were found to be negligible in this work.

\section{The sample}

The sample provided by Aldrich Chemical, Ltd. has a purity of $99 \%$. No further purification was undertaken, except for repeated pump-thaw cycles.

\section{RESULTS AND DISCUSSION}

In its electronic ground state the molecule belongs to the $C_{s}$ point group. Its 18 normal vibrational modes are all active in Raman and in infrared spectroscopy; their description, symmetry, wave numbers, and energies ${ }^{25}$ are given in Table I. $^{25}$ The valence electronic configuration is: ${ }^{14}$

$\left(1 a^{\prime \prime}\right)^{2}\left(1 a^{\prime}\right)^{2}\left(2 a^{\prime \prime}\right)^{2}\left(2 a^{\prime}\right)^{2}\left(3 a^{\prime}\right)^{2}\left(3 a^{\prime \prime}\right)^{2}\left(4 a^{\prime}\right)^{2}, \widetilde{X}^{1} A^{\prime}$.

The $\left(3 a^{\prime \prime}\right)$ and $\left(4 a^{\prime}\right)$ outermost occupied valence molecular orbitals are mostly iodine lone-pair orbitals. ${ }^{26}$ In the $C_{s}$ point group, all transitions are symmetry allowed.

Ethyl iodide is a strong $\Omega_{c} \omega$ spin-orbit coupling case. ${ }^{27}$ The correlation between the electronic states for the $C_{3 v}$ and $C_{s}$ groups is displayed in Fig. 1. The present results will be discussed in the approximate $C_{3 v}$ symmetry, which is that of $\mathrm{CH}_{3} \mathrm{I}$, as previously done. ${ }^{10,11,14}$ This means physically that the methyl group only slightly perturbs the local symmetry around the iodine atom and leads us to neglect the influence of this group on the spectroscopy of the ion and of the Rydberg states.

\section{A. The He I photoelectron spectrum}

The 9.2-10.4 eV region of the photoelectron (PE) spectrum reported in this work and shown in Fig. 2 corresponds to ionization from the Highest Occupied Molecular Orbital (HOMO) which in the $C_{3 v}$ approximation is the nonbonding molecular orbital $2 e .^{26,29,30}$ Photoejection leaves the cation in a ${ }^{2} E$ state, split into ${ }^{2} E_{3 / 2}$ and ${ }^{2} E_{1 / 2}$ by spin-orbit coupling
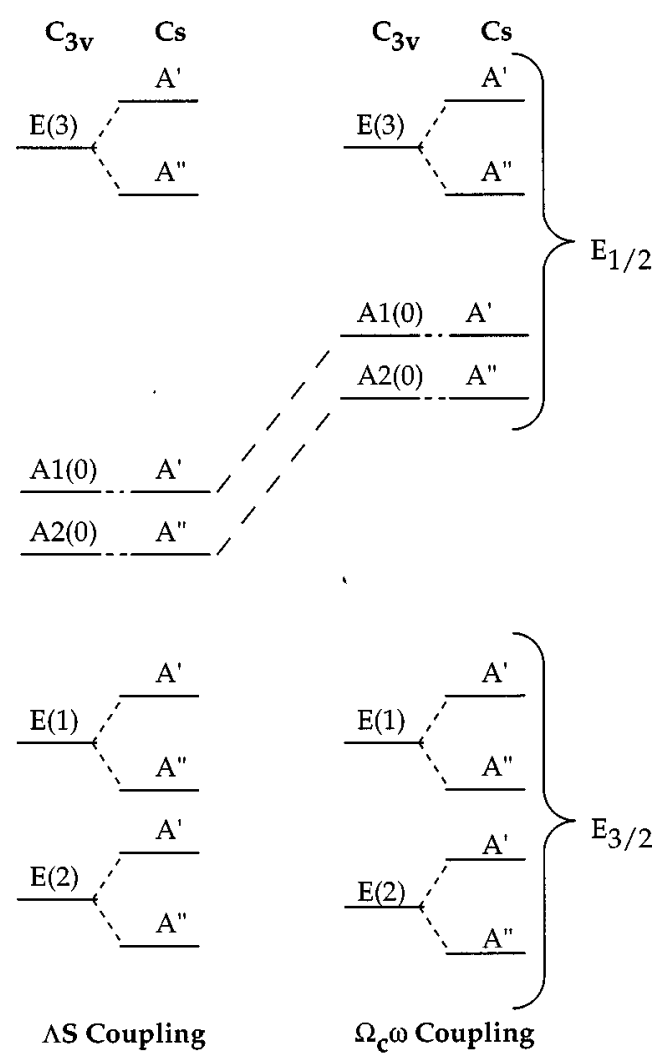

$\Lambda$ S Coupling

Ion

FIG. 1. Correlation between electronic states in $C 3 v$ and $C s$ symmetries for the two types of spin-orbit couplings. 

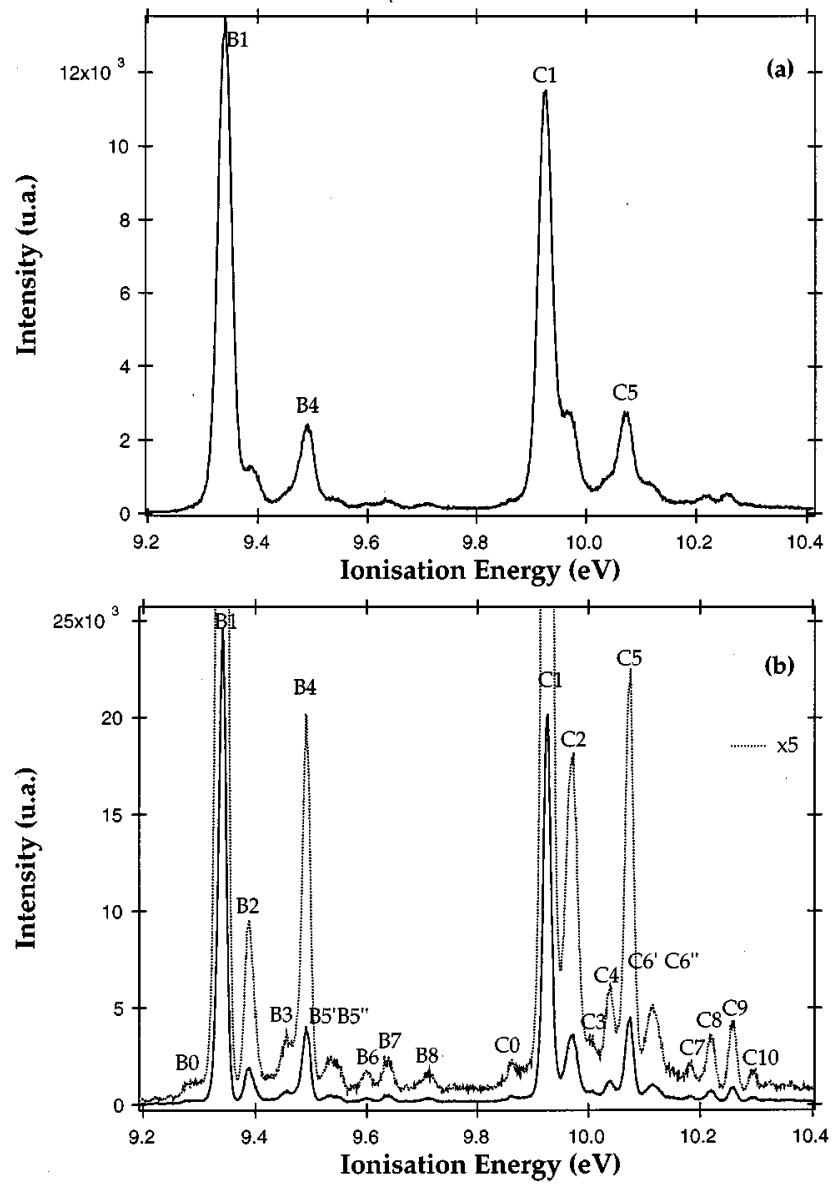

FIG. 2. High resolution $\mathrm{H}$ I photoelectron spectrum of $\mathrm{C}_{2} \mathrm{H}_{5} \mathrm{I}$ corresponding to the HOMO region. (a) Raw photoelectron spectrum. (b) Deconvoluted spectrum with peak label and enlargement in dotted line.

(Fig. 1). The spectrum shows two intense peaks, attributed to the $0-0$ transitions to the two ${ }^{2} E$ ionic states, in agreement with previous assignments. ${ }^{29}$ In addition some less intense bands, at least partly resolved for the first time, may be assigned to vibrational excitation of the ion. The ionization energies of the ${ }^{2} E_{3 / 2}$ and ${ }^{2} E_{1 / 2}$ states are found to be 9.341 $\mathrm{eV}$ and $9.927 \mathrm{eV}$, respectively, values which are in excellent agreement with the literature data (Table II). ${ }^{13,29-32}$ The spectrum is similar to that of $\mathrm{CH}_{3} \mathrm{I},{ }^{33}$ both in the nature and the energies of the normal vibration modes excited, and in the relative intensity distribution showing the assumption of $C_{3 v}$ local symmetry to be reasonable. From these consider-

TABLE II. Ionization energies and molecular ion spin-orbit splitting. Values given in $\mathrm{eV}$.

\begin{tabular}{lcccccc}
\hline \hline & This work & $\mathrm{a}$ & $\mathrm{b}$ & $\mathrm{c}$ & $\mathrm{d}$ & $\mathrm{e}$ \\
\hline$I(n)_{1}$ & $9.341 \pm 0.003$ & 9.34 & 9.35 & 9.37 & 9.35 & $9.346894+0.00025$ \\
$I(n)_{2}$ & $9.927 \pm 0.003$ & 9.93 & 9.93 & 9.93 & 9.93 & $9.929006+0.00025$ \\
$\Delta(I)$ & $0.586 \pm 0.006$ & 0.59 & 0.58 & 0.56 & 0.58 & $0.582112+0.00050$ \\
\hline \hline
\end{tabular}

${ }^{\mathrm{a}}$ Reference 29

${ }^{\mathrm{b}}$ Reference 30.

'Reference 31

${ }^{\mathrm{d}}$ Reference 32 .

${ }^{\mathrm{e}}$ Reference 13 .
TABLE III. Energy values (eV) and assignments of the vibrational structure of the He I photoelectron bands corresponding to the ionization of the HOMO. (*) The energy is given relative to the most intense band (electronic origin), $B 1$ or $C 1$.

\begin{tabular}{lcll}
\hline \hline Band & Energy* & Assignment & \multicolumn{1}{c}{ Description } \\
\hline$B 0$ & -0.063 & $1 \nu_{10}$ & $\mathrm{C}-\mathrm{I}$ stretch \\
$B 1$ & 0 & - & - \\
$B 2$ & 0.048 & $1 \nu_{10}$ & $\mathrm{C}-\mathrm{I}$ stretch \\
$B 3$ & 0.119 & $1 \nu_{9}$ & $\mathrm{C}-\mathrm{C}$ stretch \\
$B 4$ & 0.153 & $1 \nu_{7}$ & $\mathrm{CH}_{2}$ wag \\
$B 5^{\prime}$ & 0.188 & $1 \nu_{5}$ & $\mathrm{CH}_{2}$ scissors \\
$B 5^{\prime \prime}$ & 0.205 & $1 \nu_{7}+1 \nu_{10}$ & - \\
$B 6$ & 0.264 & $1 \nu_{7}+1 \nu_{9}$ & - \\
$B 7$ & 0.303 & $2 \nu_{7}$ & - \\
$B 8$ & 0.378 & $1 \nu_{2} / 1 \nu_{12}$ & $\mathrm{CH}$ stretch sym/antisym. \\
$C 0$ & -0.062 & $1 \nu_{10}$ & $\mathrm{C}-\mathrm{I}$ stretch \\
$C 1$ & 0 & - & - \\
$C 2$ & 0.045 & $1 \nu_{10}$ & $\mathrm{C}-\mathrm{I}$ stretch \\
$C 3$ & 0.079 & $2 \nu_{10}$ & - \\
$C 4$ & 0.115 & $1 \nu_{9}$ & $\mathrm{C}-\mathrm{C}$ stretch \\
$C 5$ & 0.151 & $1 \nu_{7}$ & $\mathrm{CH}_{2}$ wag \\
$C 6^{\prime}$ & 0.187 & $1 \nu_{5}$ & $\mathrm{CH}_{2}$ scissors \\
$C 6^{\prime \prime}$ & 0.203 & $1 \nu_{7}+1 \nu_{10}$ & - \\
$C 7$ & 0.261 & $1 \nu_{7}+1 \nu_{9}$ & - \\
$C 8$ & 0.300 & $2 \nu_{7}$ & - \\
$C 10$ & 0.377 & $1 \nu_{2} / 1 \nu_{12}$ & $\mathrm{CH}_{2}$ stretch sym/antisym. \\
\hline \hline
\end{tabular}

ations the vibrational analysis has been carried out with exclusion of the normal vibrational modes involving the methyl group, that is, modes $\nu_{1}, \nu_{3}, \nu_{4}, \nu_{6}, \nu_{8}, \nu_{13}, \nu_{14}, \nu_{16}$, and $\nu_{18}$ (Table I). This allows the complete interpretation of the vibrational structure of the photoelectron spectrum as discussed below.

\section{The 9.2 to $9.8 \mathrm{eV}$ region ( $B$ band)}

The 0-0 transition to the ${ }^{2} E_{3 / 2}$ state corresponds to the most intense peak, $B 1$ at $9.341 \mathrm{eV}$. At a lower energy a much less intense feature, only partly resolved [Fig. 2(b)], $B 0$ is located at $9.278 \mathrm{eV}$, i.e., $0.063 \mathrm{eV}$ below $B 1$ (see Table III). We assign this as a hot band with excitation of $1 \nu_{10}$ (C-I stretch), the energy of $0.063 \mathrm{eV}$ corresponding exactly to the $\nu_{10}$ value in the neutral molecule ground state. Feature $B 2$, partly resolved in the raw spectrum but clear in the deconvoluted one at $0.048 \mathrm{eV}$ above $B 1$, is attributed to excitation of one quantum of $\nu_{10}$. The most intense vibrational peak is $B 4$, located $0.153 \mathrm{eV}$ from the electronic origin. It is interpreted as excitation of $1 \nu_{7}\left(\mathrm{CH}_{2}\right.$ wag $)$. At higher energy one finds a broad, less intense band that could hold two contributions, namely, at $0.188 \mathrm{eV}$, excitation of $1 \nu 5\left(\mathrm{CH}_{2}\right.$ scissors $)$ and at $0.205 \mathrm{eV}$, the combination $1 \nu 7$ $+1 \nu 10$. Peak $B 8$ is attributed to excitation of $1 \nu_{2}\left(\mathrm{CH}_{2}\right.$ symmetric stretch) and/or $1 \nu_{12}\left(\mathrm{CH}_{2}\right.$ antisymetric stretch). The $B 3$ feature, partly resolved and of low intensity, is assigned to excitation of $1 \nu 9$ (C-C stretch). B6 and $B 7$ absorptions cannot be assigned to fundamental vibrational modes. They are located at $0.264 \mathrm{eV}$ and $0.303 \mathrm{eV}$, respectively, from the electronic origin, and none of the fundamental frequencies of the neutral molecule approaches these values. Accordingly, $B 6$ is taken as the combination $1 \nu_{7}$ $+1 \nu_{9}$ and $B 7$ the harmonic $2 \nu_{7}$ (Tables III and IV). ${ }^{25}$ 
TABLE IV. Vibrational energies $(\mathrm{eV})$ of $\mathrm{C}_{2} \mathrm{H}_{5} \mathrm{I}$. The energies values of the electronic ground state of the neutral molecule are taken from Ref. 25.

\begin{tabular}{|c|c|c|c|c|c|c|c|c|c|c|c|c|}
\hline Species & $\begin{array}{c}\text { Electronic } \\
\text { configuration and final } \\
\text { state }^{\mathrm{a}}\end{array}$ & $\nu_{10}^{\mathrm{b}}$ & $\nu_{10}$ & $\nu_{9}$ & $\nu_{7}$ & $\nu_{5}$ & $\nu_{2}$ & $\nu_{12}$ & $\nu_{7}+\nu_{10}$ & $\nu_{7}+\nu_{9}$ & $2 \nu_{7}$ & $2 \nu_{10}$ \\
\hline $\mathrm{C}_{2} \mathrm{H}_{5} \mathrm{I}$ & $(2 e)^{4}, \tilde{X}^{1} A_{1}$ & - & 0.063 & 0.119 & 0.150 & 0.178 & 0.369 & 0.375 & - & - & - & - \\
\hline $\mathrm{C}_{2} \mathrm{H}_{5} \mathrm{I}$ & $(2 e)^{3}\left(6 s a_{1}\right)^{1}, E(1)$ & 0.060 & 0.052 & 0.109 & 0.146 & 0.192 & - & - & - & 0.253 & 0.291 & - \\
\hline $\mathrm{C}_{2} \mathrm{H}_{5} \mathrm{I}$ & $(2 e)^{3}\left(6 s a_{1}\right)^{1}, A_{1}$ & - & 0.054 & 0.102 & - & 0.191 & 0.375 & 0.375 & - & - & - & - \\
\hline $\mathrm{C}_{2} \mathrm{H}_{5} \mathrm{I}$ & $(2 e)^{3}\left(6 s a_{1}\right)^{1}, E(3)$ & 0.062 & 0.048 & 0.107 & 0.138 & 0.184 & 0.396 & 0.396 & - & 0.246 & 0.282 & - \\
\hline $\mathrm{C}_{2} \mathrm{H}_{5} \mathrm{I}^{+}$ & $(2 e)^{3},{ }^{2} E_{3 / 2}$ & 0.063 & 0.048 & 0.119 & 0.153 & 0.188 & 0.378 & 0.378 & 0.205 & 0.264 & 0.303 & - \\
\hline $\mathrm{C}_{2} \mathrm{H}_{5} \mathrm{I}^{+}$ & $(2 e)^{3},{ }^{2} E_{1 / 2}$ & 0.062 & 0.045 & 0.115 & 0.151 & 0.187 & 0.377 & 0.377 & 0.203 & 0.261 & 0.300 & 0.079 \\
\hline
\end{tabular}

${ }^{a}$ The configuration and the final states are given in the notation of the $C_{3 v}$ approximation.

${ }^{\mathrm{b}}$ Energy value for $\nu_{10}$ in hot bands.

\section{The 9.85 to $10.35 \mathrm{eV}$ region (C band)}

The most intense peak in this region (Fig. 2) is located at $9.927 \mathrm{eV}$ and is due to the $0-0$ transition to the ${ }^{2} E_{1 / 2}$ state. The low intensity, partially resolved peak $C 0$ at $9.865 \mathrm{eV}$ $(0.062 \mathrm{eV}$ from origin $C 1)$ is assigned to a hot band, the vibrational spacing being consistent with that of $\nu_{10}$ in the neutral molecule. Feature $C 2$ is attributed to excitation of $1 \nu_{10}$ (C-I stretch) with an energy of $0.045 \mathrm{eV}$ (Tables III and IV). The most intense vibrational peak, $C 5$, located at $0.151 \mathrm{eV}$ from the 0-0 transition, is consistent with the excitation of $1 \nu_{7}\left(\mathrm{CH}_{2}\right.$ wag mode). The energy is similar to that for the same mode in the ionic state ${ }^{2} E_{3 / 2}$. The $C 6$ feature is broad, of low intensity, and asymmetric on the high energy side (Fig. 2). It could hold, at $0.187 \mathrm{eV}$, excitation of $1 \nu_{5}$ along with the combination $1 \nu_{7}+1 \nu_{10}$ at $0.203 \mathrm{eV}$. Feature $C 10$ is assigned to excitation of $1 \nu_{2} / 1 \nu_{12}$. Excitation of $1 \nu_{9}$ (peak $C 4$ ) appears $0.115 \mathrm{eV}$ above the $0-0$ transition. The combination band $1 \nu_{7}+1 \nu_{9}$ and the harmonic $2 \nu_{7}$ may be responsible for the low intensity bands at $0.261 \mathrm{eV}(C 7)$ and $0.300 \mathrm{eV}(C 8)$, respectively. The weak feature $C 3$ is assigned to the excitation of $2 \nu_{10}$ (Tables III and IV). ${ }^{25}$ The $C 9$ peak is due to the formation of $\mathrm{Xe}^{+}\left({ }^{2} P_{3 / 2}\right)$ by the $\beta$ line of $\mathrm{He}$, xenon being used for energy scale calibration.

\section{B. The electronic excitation spectrum}

The total photoabsorption spectrum presented in Fig. 3 shows a broad band of low cross section between $4 \mathrm{eV}$ and $5.5 \mathrm{eV}$ and sharp, more intense peaks above $6 \mathrm{eV}$. Note that the intensity of the features located between $9.2 \mathrm{eV}$ and 10.4 $\mathrm{eV}$ are affected by degradation in the transmission of the $\mathrm{LiF}$ windows.

\section{The $4.0-6.0 \mathrm{eV}$ region}

The lowest energy band centered at $4.78 \mathrm{eV}$ has been attributed to the excitation $n \rightarrow \sigma^{*}(\mathrm{C}-\mathrm{I})$, where $\sigma^{*}$ is anti bonding along the $\mathrm{C}-\mathrm{I}$ bond. ${ }^{28}$ The three dissociative electronic states, ${ }^{3} Q_{1}(E),{ }^{3} Q_{0}\left(A_{1}\right)$, and ${ }^{1} Q_{1}(E)$, are known to be excited at $4.135 \mathrm{eV}, 4.749 \mathrm{eV}$, and $5.170 \mathrm{eV}$ with transition probabilities of $9 \%, 81 \%$, and $10 \%$, respectively, in the optical spectrum. ${ }^{28}$

\section{The 6.0-9.7 eV region}

The region between $6 \mathrm{eV}$ and $9.7 \mathrm{eV}$, as displayed in Fig. 4(a) and (b) with peak labels, consists of many absorption peaks, most of which are interpreted in terms of Ryd-

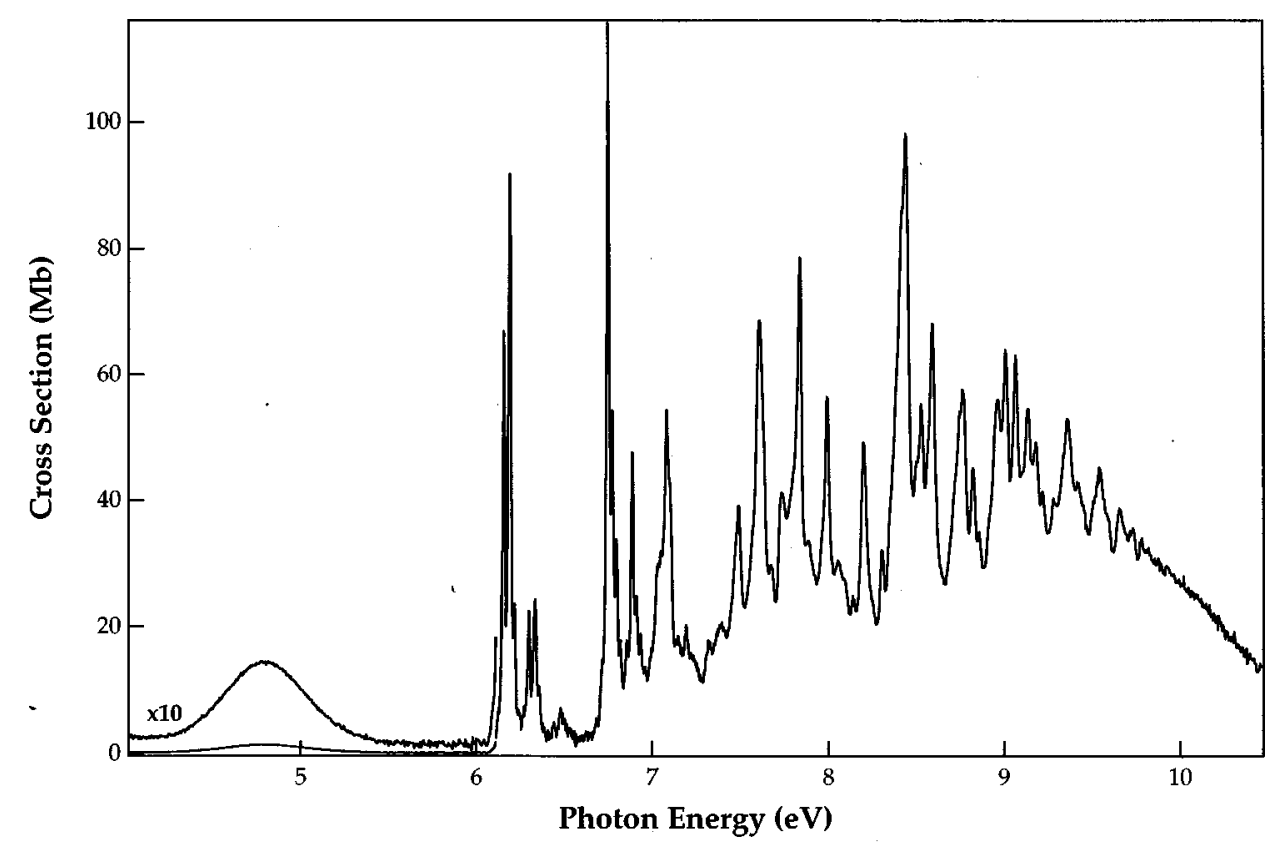

FIG. 3. High resolution photoabsorption spectrum of ethyl iodide from 4 $\mathrm{eV}$ to $10.4 \mathrm{eV}$. 

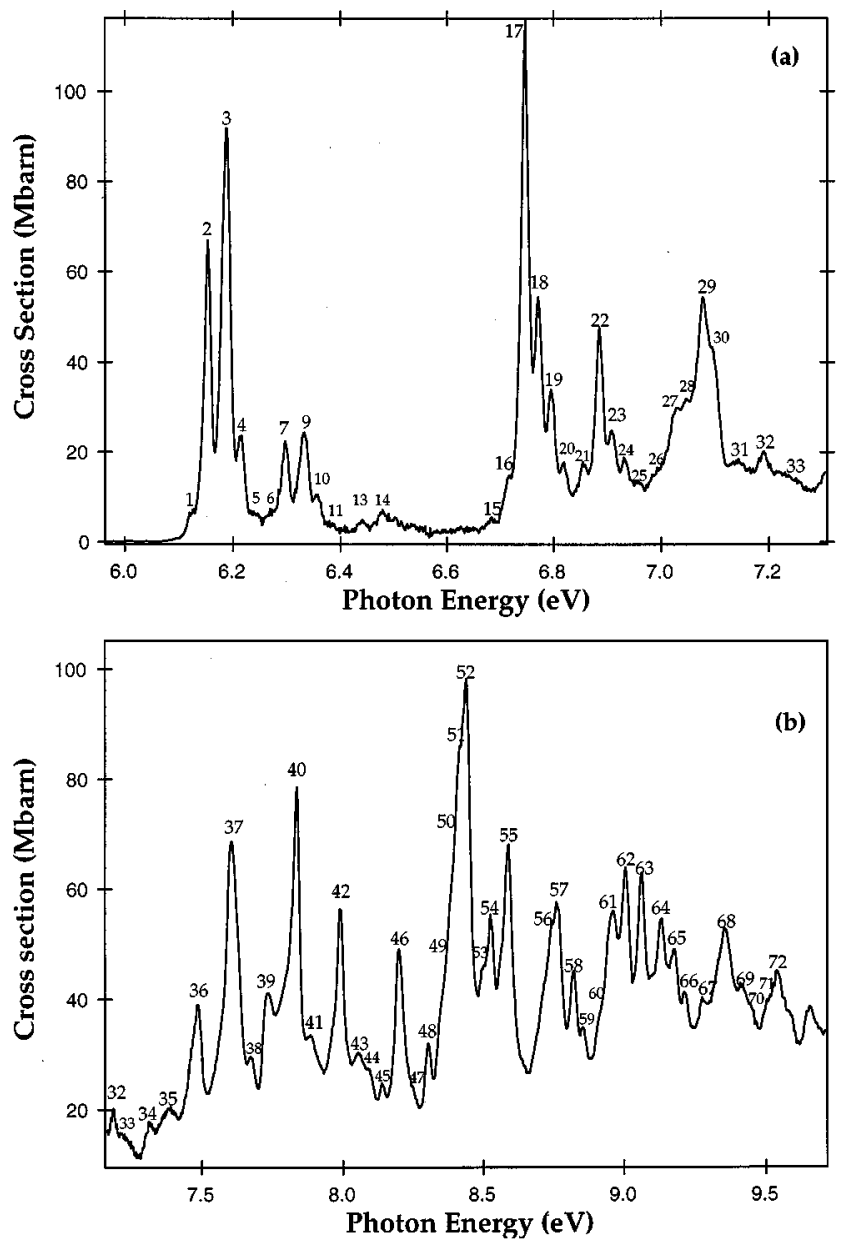

FIG. 4. High resolution photoabsorption spectra of the Rydberg states region of $\mathrm{C}_{2} \mathrm{H}_{5} \mathrm{I}$ : (a) $6.0-7.3 \mathrm{eV}$ (b) $7.2-9.7 \mathrm{eV}$.

berg series converging to the two spin-orbit components of the ionic ground state. Peak assignments have been made on the basis of the following considerations:

(1) The peak energy position, $E_{n}$, must fit the Rydberg formula: $E_{n}=E_{i}-R /(n-\delta)^{2}$, where $E_{i}$ is the ionization energy $\left(E_{i}=9.341 \mathrm{eV}\right.$ for ${ }^{2} E_{3 / 2}$ and $E_{i}=9.927 \mathrm{eV}$ for $\left.{ }^{2} E_{1 / 2}\right), n$ is the principal quantum number of the Rydberg orbital of energy $E_{n}, R$ is one Rydberg, and $\delta$ is the quantum defect. For iodine: $3.9<\delta<4.2$ for $n s,{ }^{9,14,34}$ $3.5<\delta<3.9$ for $n p,{ }^{14,34}$ and $1.8<\delta<2.7$ for $n d .{ }^{8,9,14,34}$

(2) The $0.586 \mathrm{eV}$ splitting of the ionic components.

(3) The intensity ratio of the bands. ${ }^{35}$

Table $\mathrm{V}^{8-10,14}$ gives the energy values of the photoabsorption features, the assignments to members of Rydberg series, and the excitation energies reported in previous work.

\section{The nsa $_{1}$ Rydberg series}

a. The first members $6 s a_{1}(3 / 2)$ and $6 s a_{1}(1 / 2)$. The region between 6.1 and $7.06 \mathrm{eV}$ [see Fig. 4(a)] shows two very intense features accompanied by other peaks of lower intensity. This part of the spectrum has been interpreted as arising from the transition of a lone-pair iodine electron to the Rydberg orbital $6 s a_{1} \cdot{ }^{9-12,14}$ The $0-0$ transitions to the $E(1)$ and the $E(3)$ states have been assigned to peaks 3 and 17 , respectively, these being the most intense in this region; also, their energy separation, $0.56 \mathrm{eV}$, is close to the spin-orbit splitting of the ion. The vibrational structure built on $E(1)$ (peak 3) is interpreted by comparison with the PES spectrum. Thus band 5, which is $0.052 \mathrm{eV}$ from the origin is attributed to excitation of $1 \nu_{10}$ (Table IV). ${ }^{25}$ The relatively intense peaks 7 and 9 are assigned to the excitation of $1 \nu_{9}$ and $1 \nu_{7}$, respectively. The very weak bands 13 and 14 are taken as the combination $1 \nu_{7}+1 \nu_{9}$ and the harmonic $2 \nu_{7}$, respectively. The low intensity feature 11 is assigned to the excitation of $1 \nu_{5}$ with an energy value of $0.192 \mathrm{eV}$. Feature 1 , which is not completely resolved from peak 2 , may be composite. It has been previously proposed that it is a hot band involving excitation of $1 \nu_{11} \cdot{ }^{10}$ We agree that it contains a hot band but our vibrational assignment is to mode $\nu_{10}$, as the energy spacing, $0.060 \mathrm{eV}$, is close to that of $\nu_{10}$ in the ground state of the molecule. For the $E(3)$ state [Fig. 4(a)], we propose that peak 19, partly resolved and located at $0.048 \mathrm{eV}$ from the electronic origin, is excitation of $1 \nu_{10}$ (Table IV). ${ }^{25}$ The low intensity feature 21 is supposed to be due to the excitation of $1 \nu_{9}$, energy $0.107 \mathrm{eV}$. The intense peak 22, separated by $0.138 \mathrm{eV}$ from peak 17 , is attributed to the excitation of $1 \nu_{7}$ and feature 24 to excitation of $1 \nu_{5}$ $($ energy $=0.184 \mathrm{eV}$ ). Feature 26 [Fig. 4(a)] is assigned to the combination $1 \nu_{7}+1 \nu_{9}$, feature 28 to the harmonic $2 v_{7}$ and the low intensity band 31 to excitation of $1 \nu_{2} / 1 \nu_{12}$. Peak 15 has been assigned in previous work ${ }^{10}$ to the electronic origin excitation of state $A_{1}$, but we suggest it is due to a hot band, $1 \nu_{10}$, as it is separated from peak 17 by $0.064 \mathrm{eV}$ (Table I). ${ }^{25}$

The 0-0 transition to $E(2)$ has been thought to lie at about $6.1 \mathrm{eV}$, by comparison with methyl bromide, methyl iodide, and ethyl bromide absorption spectra. ${ }^{10,11,36-38}$ In this case, band $1(6.127 \mathrm{eV})$, which we believe to contain the $1 \nu_{10} E(1)$ hot band, could also have a contribution from the 0-0 transition to $E(2)$, as it has been previously suggested. ${ }^{10}$ If the electronic origin of $E(2)$ is around band 1, then peaks $2(6.153 \mathrm{eV}), 4(6.216 \mathrm{eV})$, and $10(6.358 \mathrm{eV})$ could be interpreted in terms of vibrational structure associated with this $0-0$ transition. Alternatively, feature 2 could be the $0-0$ transition of the $E(2)$ state. However, its intensity seems too large and not consistent with the excitation of a forbidden transition in $C_{\infty V}(\Delta: \Delta \Lambda$ forbidden). As shown in Fig. 4(a), peak 2 has an intensity comparable to that of feature 3 , from which it is separated by $0.034 \mathrm{eV}$. This could be viewed as a "doubling" of feature 3. The same prevails for the pair of peaks $7(6.296 \mathrm{eV})$ and $9(6.333 \mathrm{eV})$, separated by $0.037 \mathrm{eV}$. This has been previously interpreted in terms of the splitting of the $E$ states into $A^{\prime}$ and $A^{\prime \prime} .{ }^{12}$ However, such a doubling is not observed around peak 17 , which has been assigned to the transition to $E(3)$, nor for the $7 s a_{1}$ Rydberg state region [see Fig. 4(b)]. This could be explained by invoking a vibronic doubling as has been reported in the case of ethyl bromide. $^{38}$ The vibronic doubling of the $E(1)$ state could be caused by the excitation of $1 \nu_{10}$ of the $0-0$ transition to $E(2)$. This suggestion should to be checked by measurements on the deuteriated molecule $\left(\mathrm{C}_{2} \mathrm{D}_{5} \mathrm{I}\right)$.

The 0-0 transition to $A_{1}$ is assigned to peak 16 located at 
TABLE V. Energy values (eV) of the absorption bands and assignments for the Rydberg states.

\begin{tabular}{|c|c|c|c|c|c|c|c|c|}
\hline \multicolumn{4}{|c|}{ Components $(3 / 2)$} & \multicolumn{4}{|c|}{ Components $(1 / 2)$} & \multirow[b]{2}{*}{ Attribution } \\
\hline Peak & $\begin{array}{l}\text { This } \\
\text { work }\end{array}$ & $\begin{array}{c}\text { Previous } \\
\text { work }\end{array}$ & $\delta$ & Peak & $\begin{array}{l}\text { This } \\
\text { work }\end{array}$ & $\begin{array}{c}\text { Previous } \\
\text { work }\end{array}$ & $\delta$ & \\
\hline 3 & 6.187 & $\begin{array}{l}6.195^{\mathrm{a}} \\
6.196^{\mathrm{b}} \\
6.195^{\mathrm{d}}\end{array}$ & 3.92 & 17 & 6.747 & $\begin{array}{l}6.752^{\mathrm{a}, \mathrm{d}} \\
6.749^{\mathrm{b}}\end{array}$ & 3.93 & $6 s a_{1}$ \\
\hline 40 & 7.835 & $7.980^{\mathrm{d}}$ & 4.00 & 52 & 8.437 & $8.573^{d}$ & 3.98 & $7 s a_{1}$ \\
\hline 54 & 8.526 & $8.573^{d}$ & 3.93 & 62 & 9.005 & $9.161^{\mathrm{d}}$ & 4.16 & $8 s a_{1}$ \\
\hline 58 & 8.820 & $8.810^{\mathrm{d}}$ & 3.90 & 68 & 9.355 & $9.417^{d}$ & 4.13 & $9 s a_{1}$ \\
\hline 61 & 8.962 & $8.984^{\mathrm{d}}$ & 4.06 & 72 & 9.539 & & 3.90 & $10 s a_{1}$ \\
\hline 63 & 9.062 & & 4.09 & 74 & 9.652 & & 3.90 & $11 s a_{1}$ \\
\hline 64 & 9.134 & & 4.00 & & & & & $12 s a_{1}$ \\
\hline 41 & 7.883 & & 3.84 & 52 & 8.437 & & 3.89 & $7 p a_{1}$ \\
\hline 43 & 8.053 & $8.198^{d}$ & 3.62 & 55 & 8.589 & $8.750^{d}$ & 3.71 & $7 p e$ \\
\hline 53 & 8.500 & $8.650^{\mathrm{d}}$ & 3.74 & 63 & 9.062 & $9.260^{\mathrm{d}}$ & 3.83 & $8 p e$ \\
\hline 57 & 8.759 & & 3.73 & 68 & 9.355 & & 3.74 & $9 p e$ \\
\hline 29 & 7.077 & $7.484^{\mathrm{d}}$ & 2.55 & 37 & 7.605 & $8.063^{d}$ & 2.58 & $5 d a_{1}$ \\
\hline \multirow[t]{2}{*}{36} & 7.488 & $7.823^{\mathrm{d}}$ & 2.29 & 42 & 7.988 & $8.412^{\mathrm{d}}$ & 2.35 & $5 d e$ \\
\hline & & & & 39 & 7.731 & & 2.51 & $5 d e$ \\
\hline 40 & 7.835 & & 2.00 & 50 & 8.416 & & 2.00 & $5 d e$ \\
\hline 46 & 8.198 & $8.305^{\mathrm{d}}$ & 2.55 & 57 & 8.759 & $8.898^{\mathrm{d}}$ & 2.59 & $6 d a_{1}$ \\
\hline 49 & 8.357 & $8.501^{\mathrm{d}}$ & 2.29 & 60 & 8.917 & $9.056^{\mathrm{d}}$ & 2.33 & $6 d e$ \\
\hline 50 & 8.416 & & 2.17 & 63 & 9.062 & & 2.04 & $6 d e$ \\
\hline \multirow[t]{2}{*}{56} & 8.743 & $8.756^{c}$ & 2.25 & 68 & 9.355 & $9.346^{c}$ & 2.13 & $7 d e$ \\
\hline & & $8.750^{\mathrm{d}}$ & & & & $9.351^{\mathrm{d}}$ & & \\
\hline \multirow[t]{2}{*}{60} & 8.917 & $8.941^{\mathrm{c}}$ & 2.37 & 71 & 9.503 & $9.522^{c}$ & 2.34 & $8 d e$ \\
\hline & & $8.956^{\mathrm{d}}$ & & & & $9.525^{\mathrm{d}}$ & & \\
\hline \multirow[t]{2}{*}{63} & 9.062 & $9.052^{c}$ & 2.09 & & & $9.635^{c}$ & & $9 d e$ \\
\hline & & $9.056^{\mathrm{d}}$ & & & & $9.626^{\mathrm{d}}$ & & \\
\hline \multirow[t]{2}{*}{64} & 9.134 & $9.122^{c}$ & 2.01 & & & $9.075^{\mathrm{c}}$ & & $10 d e$ \\
\hline & & $9.113^{\mathrm{d}}$ & & & & $9.709^{d}$ & & \\
\hline \multirow[t]{2}{*}{65} & 9.179 & $9.170^{c}$ & 2.00 & & & $9.751^{\mathrm{c}}$ & & $11 d e$ \\
\hline & & $9.160^{\mathrm{d}}$ & & & & $9.763^{d}$ & & \\
\hline
\end{tabular}

${ }^{\text {a }}$ Reference 9.

${ }^{\mathrm{b}}$ Reference 10.

$6.717 \mathrm{eV}$. Peak $18(6.771 \mathrm{eV})$ is $0.054 \mathrm{eV}$ from the electronic origin, and so is assigned to the excitation of $1 \nu_{10}$. Feature 20, at $0.102 \mathrm{eV}$ from peak 16 , is assigned to the excitation of $1 \nu_{9}$, and feature 23 , spacing $0.191 \mathrm{eV}$, to the excitation of $1 \nu_{5}$. These energy values are close to the corresponding ones found for the $E(1)$ state as well as for the ion (Table IV). ${ }^{25}$ We suggest that feature 30 , partly resolved from peak 29, is due to the excitation of $1 \nu_{2} / 1 \nu_{12}$.

$b$. The $n s a_{1}$ members for $n>6$. At higher energies, features 40, 54, and 58 [Fig. 4(b)] are attributed to the excitation of the $n=7,8$, and 9 members of the $n s a_{1}$ Rydberg series converging to the ionic level $\widetilde{X}^{2} E_{3 / 2}$ (Table V). ${ }^{8-10,14}$ The value of the quantum defect varies from 4 to 3.9, and the intensity of these members decrease as $n^{3}$. The absorption peaks located at $8.962 \mathrm{eV}(61), 9.062 \mathrm{eV}(63)$, and $9.134 \mathrm{eV}$ (64) [Fig. 4(b)] could correspond to members of the series having $n=10,11$, and 12 , respectively, with $\delta$ varying from 4.09 to 4.0, but their intensities do not follow the decreasing $n^{3}$ law of the series. This could be explained by the presence of overlapping bands due to the excitation of members of $n d$ series at very close energies (see below). Features observed at $9.005 \mathrm{eV}(62), 9.355 \mathrm{eV}$ (68), and $9.539 \mathrm{eV}$ (72) (Table V) are assigned to the $n=8,9$, and 10 members of the $n s a_{1}(1 / 2)$ Rydberg series; their intensity seems to follow the
${ }^{\mathrm{c}}$ Reference 8 .

${ }^{\mathrm{d}}$ Reference 14.

$n^{3}$ dependence. Feature 52 at $8.437 \mathrm{eV}$ is rather broad and may hold several members of different series, all very close in energy, as well as the $7 s a_{1}(1 / 2)$ state (Table V). ${ }^{8-10,14} \mathrm{We}$ suggest assignment of the $11 s a_{1}(1 / 2)$ term to peak 74 , located at $9.652 \mathrm{eV}$. In this series, the quantum defect varies from 3.90 to 4.16 .

c. The $n d \lambda$ Rydberg series. We have attributed the region between $7.077 \mathrm{eV}$ and $8.42 \mathrm{eV}$ (Fig. 4) to excitation of the $5 d \lambda$ series. As features 29 and 37 are separated by 0.528 $\mathrm{eV}$, close to the molecular ion splitting, they are linked with transitions to the same Rydberg orbital but to the ${ }^{2} E_{3 / 2}$ and ${ }^{2} E_{1 / 2}$ limits, respectively. We attribute peak 29 to the $5 d a_{1}(3 / 2)$ and peak 37 to $5 d a_{1}(1 / 2)$, the quantum defects of 2.55 and 2.58 being consistent with a $n d$ Rydberg orbital. At energies above peak 29 there are at least four features of much lower intensity (Fig. 4) which seem to be due to vibrational excitation of the Rydberg state. Feature 32 and 33, separated from peak 29 by $0.114 \mathrm{eV}$ and $0.150 \mathrm{eV}$, respectively, may correspond to excitation of $1 \nu_{9}$ and $1 \nu_{7}$, respectively. Bands 34 and 35 can be interpreted as excitation of a combination band $1 \nu_{7}+1 \nu_{9}$ and of $2 \nu_{7}$, respectively. The peaks located at $7.488 \mathrm{eV}$ (36) and $7.988 \mathrm{eV}$ (42) are taken to correspond to the two members $5 \mathrm{de}$ already reported, ${ }^{14}$ with quantum defects of 2.29 and 2.35 , respectively. Peaks 


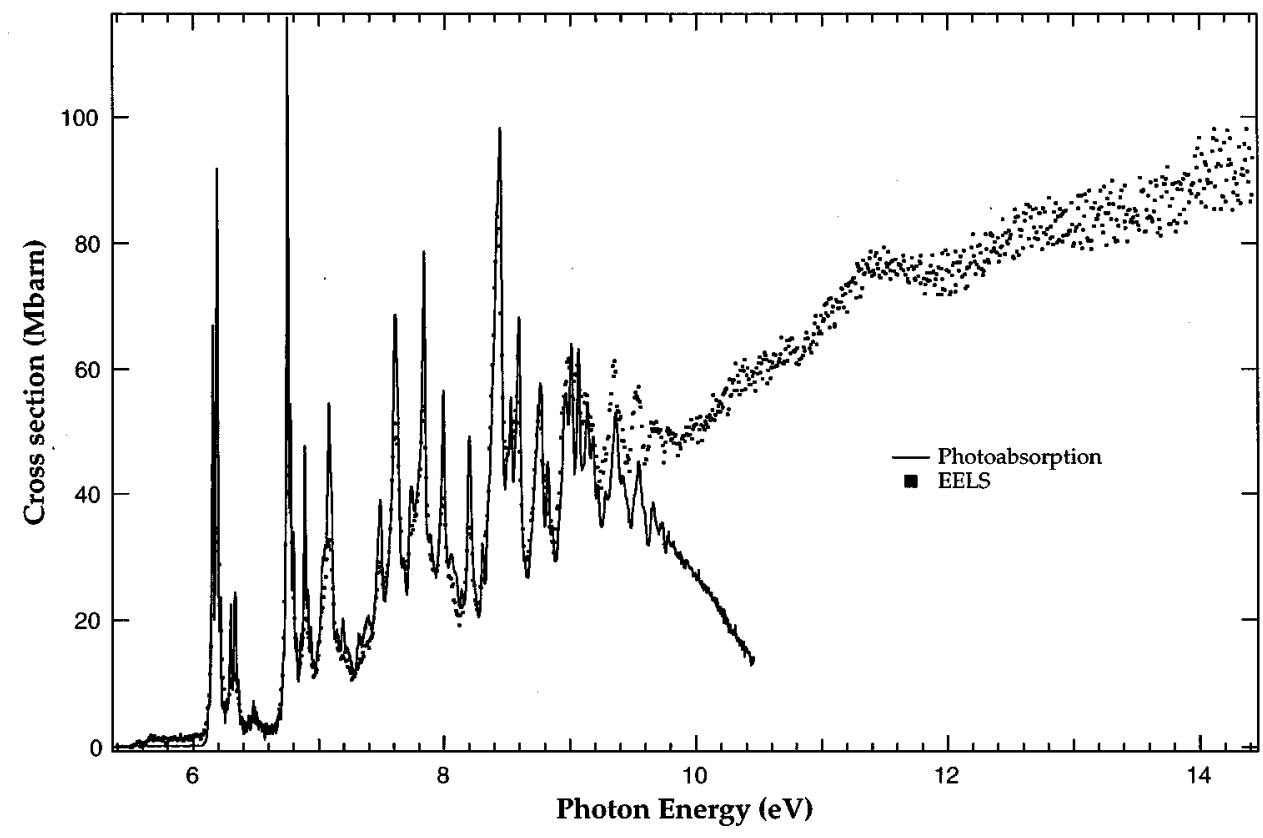

FIG. 5. Comparison of the $\mathrm{C}_{2} \mathrm{H}_{5} \mathrm{I}$ photoabsorption spectrum with the Electron Energy Loss spectrum. For this, the EELS data were normalized to the photoabsorption cross section value at $7.276 \mathrm{eV}$.
46 and 57, centered at $8.198 \mathrm{eV}$ and $8.759 \mathrm{eV}$, respectively, are attributed to the excitation of the members $6 d a_{1}$ converging to the two limits of the ion, with quantum defects very close to that for $5 d a_{1}(3 / 2)$ and $5 d a_{1}(1 / 2)$ (Table V). ${ }^{8-10,14}$ For the $6 d e$ terms, we suggest peak 49 for the $3 / 2$ limit and peak 60 for the $1 / 2$ limit, with $\delta=2.29$ and 2.33, respectively. The features at $8.743 \mathrm{eV}(56)$ and at $9.355 \mathrm{eV}$ (68) are assigned to excitation of the $7 d e$ orbital, the $\delta$ value of 2.25 and 2.13 , respectively, being compatible with transitions to nde orbitals. We assign the low intensity features 60 and 71 to the $n=8$ members of these $n d e(3 / 2)$ and $(1 / 2)$ series. The $n=10$ and 11 terms of the $n d e(3 / 2)$ series may be located at $9.134 \mathrm{eV}(64)$ and $9.179 \mathrm{eV}$ (65), respectively, $\delta$ being consistent with the assignments. The transition to the $n=9$ member of this $d e(3 / 2)$ series may overlap with peak $63\left(11 s a_{1}\right)$. The absorption bands of the corresponding members of the $(1 / 2)$ series fall outside the spectral range of this work.

d. The $n p \lambda$ Rydberg series. The $n p \lambda$ Rydberg series are expected to be less intense than the $n s$ and $n d$ ones, considering the atomic selection rule of $\Delta 1= \pm 1$. The very weak feature 41 [Fig. 4(b)] could correspond to the excitation of a $7 p a_{1}(3 / 2)$ member, with a $\delta$ of 3.84 , which is consistent with that kind of series. The member $7 p a_{1}(1 / 2)$ may contribute, along with overlapping transitions, to band 52 (Table $\mathrm{V})^{8-10,14}$ which is much broader than the other peaks located in this energy region; the splitting, $0.55 \mathrm{eV}$, is close to the energy difference between the components of the molecular ion in its ground state. The low intensity bands 43 and 53 may be due to excitation of the $n=7$ and 8 members, respectively, of the npe(3/2) series.

The $n=7$ and 8 members of the series converging to the $1 / 2$ limit are placed within bands 55 and 63 , which contain $6 d e(1 / 2)$ and $10 d e(3 / 2)$, respectively. The $n=9$ members of the npe series may lie within peaks 57 , for the $3 / 2$ limit and 68 for the 1/2 limit, respectively, as the bandwidths of these spectral features are rather large.

\section{Differential and optical oscillator strengths}

The electronic excitation spectra of ethyl iodide measured by photoabsorption and by EELS are displayed in Fig. 5 for the $5.8 \mathrm{eV}-14.2 \mathrm{eV}$ region. Comparison of the optical absorption cross sections values with those of the EELS data shows that the optical measurements were free of line saturation effects. Moreover, the EEL spectrum gives access to the oscillator strength values up to $14.2 \mathrm{eV}$, that is, into a region which cannot be reached by photoabsorption in our experiment.

For the lowest energy valence absorption band, the cross section value reported in Fig. 3 agrees with that deduced from the extinction coefficient ${ }^{9,39}$ and with that measured previously ${ }^{2,3}$ at $260 \mathrm{~nm}$.

For the Rydberg state region, as shown in Fig. 5, the photoabsorption spectrum is similar to the normalized EEL spectrum. Differences arise only from different resolution between the two experiments. Table VI gives the optical oscillator strength values measured by EELS and optical UV photoabsorption. The electron impact data and the photoabsorption data match until $9.2 \mathrm{eV}$. This confirms that the photoabsorption cross section values are free of line saturation effects, and are accurate up to $9.2 \mathrm{eV}$. At higher energy, from 9.2 to $10.457 \mathrm{eV}$ (the limit of the present optical spectrum), the two values diverge but we know this to be due to degradation in the transmission of the LiF windows. The EEL data are therefore preferred from 9.2 to $14.2 \mathrm{eV}$ as absolute cross section measurements.

\section{CONCLUSIONS}

The electronic spectroscopy of ethyl iodide has been studied in the 4-14.2 eV region by both high resolution photoabsorption and electron impact. Tentative assignments in the spectral region corresponding to electronically excited states involving electron transitions from the highest occupied molecular orbital into the $6 s$ Rydberg orbital have been 
TABLE VI. Oscillator strengths for $\mathrm{C}_{2} \mathrm{H}_{5} \mathrm{I}$ bands.

\begin{tabular}{ccc}
\hline \hline & $\begin{array}{c}\text { Optical oscillator strength } \\
\text { Photoabsorption }\end{array}$ & EELS \\
\hline $6.02-6.59$ & 0.056 & 0.045 \\
$6.59-7.26$ & 0.131 & 0.104 \\
$7.26-8.10$ & 0.251 & 0.227 \\
$8.10-8.68$ & 0.225 & 0.218 \\
$8.68-9.2$ & 0.214 & 0.226 \\
$9.2-9.69$ & - & 0.228 \\
$9.69-10.46$ & - & 0.371 \\
$10.46-12.02$ & - & 1.022 \\
$12.02-14.21$ & - & 1.67 \\
\hline \hline
\end{tabular}

made by comparison with the high resolution photoelectron spectrum related to the HOMO. The suggested splitting of the $E$ level into $A^{\prime}$ and $A^{\prime \prime}$ components ${ }^{12}$ is not observed. The present analysis shows methyl iodide, and consequently the $C_{3 v}$ approximation, to be a good model for the interpretation of higher alkyl iodides such as ethyl iodide. Our attribution of the electronic origins of the $E(1)$ and $E(3)$ states to the most intense spectral peaks leads to a near-complete account of the observed vibrational fine structure. However, the assignment of the transitions to the $E(2)$ and $A_{1}$ states are still uncertain. The possibility of a vibronic doubling occurring for the transition to $E(1)$ is proposed; this should be further investigated by, for example, measurements on the deuteriated analogue.

We also report here new members of Rydberg series such as $n=11$ and 12 Rydberg states for the series $n s a_{1}$. We confirm the previous attribution of the $5 \mathrm{de}$ series. ${ }^{14}$

Oscillator strength values have also been measured by EELS and VUV photoabsorption in the region of 6-14.2 eV. These data could be used as standards for any future photoabsorption experiment.

\section{ACKNOWLEDGMENTS}

This research has been supported by the Patrimoine of the University of Liège and by the Fonds National de la Recherche Scientifique. It has been funded in part by the EPSRC and CLRC of the United Kingdom. M.J.H.F. and F.M.T. wish to acknowledge the Fond National de la Recherche Scientifique for position and support. J.M.G. and N.C.J. recognize the provision of EPSRC postgraduate studentship. N.J.M. recognizes the support of the Royal Society. M.J.H.F., N.J.M., J.M.G., and N.C.J. are grateful to NATO for a collaborative research grant. M.J.H.F. benefits of a INTAS contract.
${ }^{1}$ D. Krajnovitch, L. J. Buttler, and Y. T. Lee, J. Chem. Phys. 81, 3031 (1984).

${ }^{2}$ C. M. Roehl, J. M. Burkholder, G. K. Moortgat, A. R. Ravinshankara, and P. J. Crutzen, J. Geophys. Res. 102, 12819 (1997)

${ }^{3}$ O. V. Rattigan, D. E. Shallcross, and R. Cox, J. Chem. Soc., Faraday Trans. 93, 2839 (1997).

${ }^{4}$ W. L. Chameides and D. D. Davis, J. Geophys. Res. 85, 7383 (1980).

${ }^{5}$ A. Paul, M. X. Yang, and B. E. Bent, Surf. Sci. 297, 327 (1993).

${ }^{6}$ M. X. Yang, S. K. Jo, A. Paul, L. Avila, B. E. Bent, and K. Nishikida, Surf. Sci. 325, 102 (1995).

${ }^{7}$ G. Scheibe, F. Povenz, and C. Lindstrom, Z. Phys. Chem. Abt. B 20, 283 (1933)

${ }^{8}$ W. C. Price, J. Chem. Phys. 4, 457 (1936).

${ }^{9}$ R. A. Boschi and D. R. Salahub, Mol. Phys. 24, 289 (1972).

${ }^{10}$ N. L. Baker and B. R. Russel, J. Mol. Spectrosc. 69, 221 (1978).

${ }^{11}$ D. H. Parker, R. Pandolfi, P. R. Stannard, and M. A. El-Sayed, Chem. Phys. 45, 27 (1980).

${ }^{12}$ E. Lane, P. Brint, M. Tziraki, and S. Couris, J. Chem. Soc., Faraday Trans. 91, 3083 (1995).

${ }^{13}$ M. A. Baig, J. P. Connerade, and J. Hormes, J. Phys. B 19, L343 (1986).

${ }^{14}$ A. Bouguerne, M. J. Hubin-Franskin, and M. Furlan, J. Phys. B 27, 199 (1994).

${ }^{15}$ J. Delwiche, P. Natalis, J. Momigny, and J. E. Collin, J. Electron Spectrosc. 1, 219 (1972).

${ }^{16}$ F. Motte-Tollet, J. Delwiche, J. Heinesh, M.-J. Hubin-Franskin, J. M. Gingell, N. C. Jones, N. J. Mason, and G. Marston, Chem. Phys. Lett. 284, 452 (1998).

${ }^{17}$ J. H. D. Eland, Photoelectron Spectroscopy, 2nd ed. (Butterworth \& Co., Ltd., London, 1984).

${ }^{18}$ P. H. Van Cittert, Z. Phys. 69, 298 (1931).

${ }^{19}$ J. D. Allen, Jr. and F. A. Grimm, Chem. Phys. Lett. 66, 72 (1979).

${ }^{20}$ M. H. Palmer, I. C. Walker, M. F. Gust, and M. R. F. Siggel, Chem. Phys. 201, 381 (1995).

${ }^{21}$ M. Furlan, M.-J. Hubin-Franskin, J. Delwiche, D. Roy, and J. E. Collin, J. Chem. Phys. 82, 1797 (1985).

${ }^{22}$ F. Motte-Tollet, M.-J. Hubin-Franskin, and J. E. Collin, J. Chem. Phys. 97, 7314 (1992)

${ }^{23}$ F. Motte-Tollet, J. Heinesch, J. M. Gingell, and N. J. Mason, J. Chem. Phys. 106, 5990 (1997).

${ }^{24}$ R. H. Huebner, R. J. Celotta, S. R. Mielczarek, and C. E. Kuyatt, J. Chem. Phys. 59, 5434 (1973).

${ }^{25}$ J. R. Durig, J. W. Thompson, V. W. Thyagean, and J. D. Witt, J. Mol. Struct. 24, 41 (1975).

${ }^{26}$ R. G. Dromey and J. B. Pell, J. Mol. Struct. 23, 53 (1974).

${ }^{27}$ Herzberg, Molecular Spectra and Molecular Structure, Vol. III, Electronic Spectra and Electronic Structure of Polyatomic Molecule (Van Nostrand, Toronto, 1966).

${ }^{28}$ A. Gedanken, Chem. Phys. Lett. 137, 462 (1987).

${ }^{29}$ K. Kimura, S. Katsumata, Y. Achiba, H. Matsumoto, and S. Nagakura, Bull. Chem. Soc. Jpn. 46, 373 (1973).

${ }^{30}$ R. A. Boschi and D. R. Salahub, Can. J. Chem. 52, 1217 (1974).

${ }^{31}$ F. Brogli and E. Heilbronner, Helv. Chim Acta 54, 1423 (1971).

${ }^{32}$ A. D. Baker, D. Betteridge, N. R. Kemp, and R. P. Kirby, Anal. Chem. 43, 375 (1970).

${ }^{33}$ L. Karlsson, R. Jadrny, L. Mattsson, F. T. Chan and K. Siegbahn, Phys. Scr. 16, 25 (1977)

${ }^{34}$ A. B. F. Duncan, Rydberg Series in Atoms and Molecules (Academic, New York, 1971)

${ }^{35}$ R. S. Mulliken, Phys. Rev. 61, 277 (1942).

${ }^{36}$ S. Felps, P. Hochmann, P. Brint, and S. P. McGlynn, J. Mol. Spectrosc. 59, 355 (1976).

${ }^{37}$ J. D. Scott, W. S. Felps, G. L. Findley, and S. P. McGlynn, J. Chem. Phys. 68, 4678 (1978).

${ }^{38}$ W. S. Felps, J. D. Scott, G. L. Findley, and S. P. McGlynn, J. Chem. Phys. 74, 4832 (1981)

${ }^{39}$ A. Astoin, J. M. Garnier, and M. Cordier, J. Phys. 19, 507 (1958). 